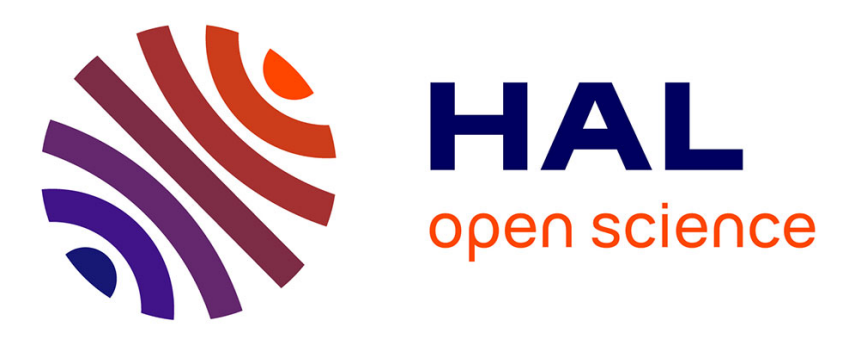

\title{
Magnetically-controllable hollow multi-shell magnetite spheres as stable and reusable SERS substrates
}

Yu-Fang Huang, Wen-Chi Huang, Pei-Kai Hsu, Jenn-Ming Song, Alexandre Gloter, Shih-Yun Chen

\section{- To cite this version:}

Yu-Fang Huang, Wen-Chi Huang, Pei-Kai Hsu, Jenn-Ming Song, Alexandre Gloter, et al.. Magnetically-controllable hollow multi-shell magnetite spheres as stable and reusable SERS substrates. Applied Surface Science, 2021, 536, pp.147705. 10.1016/j.apsusc.2020.147705 . hal-03009768

\section{HAL Id: hal-03009768 https://hal.science/hal-03009768}

Submitted on 17 Nov 2020

HAL is a multi-disciplinary open access archive for the deposit and dissemination of scientific research documents, whether they are published or not. The documents may come from teaching and research institutions in France or abroad, or from public or private research centers.
L'archive ouverte pluridisciplinaire HAL, est destinée au dépôt et à la diffusion de documents scientifiques de niveau recherche, publiés ou non, émanant des établissements d'enseignement et de recherche français ou étrangers, des laboratoires publics ou privés. 


\title{
Magnetically-controllable hollow multi-shell magnetite spheres as stable and reusable SERS substrates
}

\author{
Yu-Fang Huang ${ }^{\mathrm{a}, \mathrm{b}}$, Wen-Chi Huang ${ }^{\mathrm{a}}$, Pei-Kai Hsu ${ }^{\mathrm{a}}$, Jenn-Ming Song ${ }^{\mathrm{c}, \mathrm{d}, \mathrm{e}, *}$, Alexandre Gloter ${ }^{\mathrm{f}}$, \\ Shih-Yun Chen ${ }^{\mathrm{a}, *}$ \\ a Department of Materials Science and Engineering, National Taiwan University of Science and Technology, Taipei, Taiwan \\ ${ }^{\mathrm{b}}$ Material and Chemical Research Laboratories, Industrial Technology Research Institute, Hsinchu, Taiwan \\ ${ }^{\mathrm{c}}$ Department of Materials Science and Engineering, National Chung Hsing University, Taichung, Taiwan \\ ${ }^{\mathrm{d}}$ Research Center for Sustainable Energy and Nanotechnology, National Chung Hsing University, Taichung 402, Taiwan \\ e Innovation and Development Center of Sustainable Agriculture, National Chung Hsing University, Taichung 402, Taiwan \\ ${ }^{\mathrm{f}}$ Laboratoire de Physique des Solides, Université Paris-Saclay, CNRS UMR 8502, F-91405 Orsay, France
}

\begin{abstract}
A B S T R A C T
This study successfully synthesized magnetically-manipulatable and reusable SERS active buoyant substrates, i.e. $\mathrm{Ag} @ \mathrm{SiO}_{2} @ \mathrm{Fe}_{3} \mathrm{O}_{4}$ composite hollow spheres. The composites comprised mesoscopic hollow spheres with a $\mathrm{Fe}_{3} \mathrm{O}_{4}$ inner shell of $15-30 \mathrm{~nm}$ in thickness and strong ferromagnetism, which were synthesized using spray pyrolysis and the subsequent reduction, and a $\mathrm{SiO}_{2}$ outer shell to maintain the stability of $\mathrm{Fe}_{3} \mathrm{O}_{4}$, as well as $\mathrm{Ag}$ nanoparticles on the sphere surface providing localized surface plasmon resonance. The coercive field $\left(\mathrm{H}_{\mathrm{c}}\right)$ of bare $\mathrm{Fe}_{3} \mathrm{O}_{4}$ hollow sphere reached $200 \mathrm{Oe}$, and the saturation magnetization $\left(\mathrm{M}_{\mathrm{s}}\right)$ was $130 \mathrm{emu} / \mathrm{g}$ at $300 \mathrm{~K}$, which was at least $30 \%$ higher than the reported values no matter in bulk or nanoscales. Compared to composite spheres with $\mathrm{Fe}_{3} \mathrm{O}_{4}$ solid cores, the SERS signal intensity of hollow structures was 2.6 times greater, which could be attributed to the buoyancy of hollow structure which contribute to more interaction with the target analytes. Under external magnetic field, these ferromagnetic hollow composites can be concentrated and separated easily, resulting in a more augmented SERS effect (about 1.5 times higher than those collected without applying magnetic field). This study also demonstrated the possibility to reuse those composites for SERS measurements.
\end{abstract}

\section{Introductions}

In the last decades, numerous works have been devoted to improve surface enhanced Raman scattering (SERS) detection techniques, in particular, the design and synthesis of SERS substrates. SERS arises from the electromagnetic enhancement, which is induced by local surface plasmon resonance of colloidal or immobilized noble metal nanoparticles (NPs) [1-3]. SERS has been widely used in various fields, including biology, medical pharmacy, materials science, electrochemistry, environmental monitoring, health monitoring, etc.

Many methods have been proposed to intensify SERS signals. The application of magnetic materials as a part of SERS substrate is an important one. With the assistance of magnetic matters in SERS substrates, the detection sensitivity could be improved and the substrate recycling becomes approachable, since magnetism can be used to concentrate and collect SERS substrates from the solution [4-7]. Considerable research efforts have been devoted to the synthesis of functionalized magnetic materials as SERS substrates [8,9], for instance, iron oxides, which have attracted much interest owing to their unique magnetic properties, biocompatibility, and high chemical stability [10]. With $\mathrm{Ag}$ or Au decorated on the surface, $\mathrm{Fe}_{2} \mathrm{O}_{3}$ and $\mathrm{Fe}_{3} \mathrm{O}_{4}$ in the forms of nanoparticles, nanospheres and dumbbells have been applied as SERS substrates to detect different analytes in liquids [4-6].

Based on the concept of the "Lab on a bubble" [11], hollow spheres have been proposed for SERS substrates. Hollow structures have many advantages, including larger specific surface area, better dispersibility in liquid media, and greater ability of the particles to withstand volumetric cycle changes [12]. It has been reported that both the size and the shape make impact on the magnetic properties of iron oxides $[13,14]$. Compared to flat surfaces, a higher coercivity and remanence will be observed as in nanobowls and macroporous films, since the curved surfaces pin more domain walls $[15,16]$.

In this study, we develops a stable and reusable LoB structure which exhibit excellent SERS performance, i.e. Ag nanoparticle-decorated 


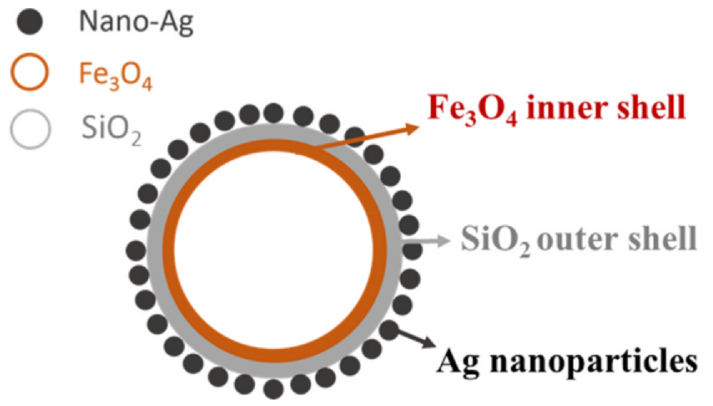

Fig. 1. Magnetically manipulatable 3D SERS substrates developed in this study.

hollow $\mathrm{SiO}_{2} / \mathrm{Fe}_{3} \mathrm{O}_{4}$ composite spheres. As illustrated in Fig. 1, $\mathrm{Fe}_{3} \mathrm{O}_{4}$ hollow spheres synthesized using spray pyrolysis are buoyant and magnetically manipulatable. A thin $\mathrm{SiO}_{2}$ outer shell can isolate $\mathrm{Fe}_{3} \mathrm{O}_{4}$ from the environment and also eliminate the undesired Raman scattering signal from $\mathrm{Fe}_{3} \mathrm{O}_{4}[17,18,19]$. Plasmonic $\mathrm{Ag}$ nanoparticles deposited on the sphere surface are able to enhance Raman signals. The phase identification of iron oxides and the composites will be performed by electron energy loss spectrum (EELS), and the magnetic properties will also be investigated. The SERS effect of the hollow composite spheres will be evaluated by Raman spectra of Rhodamine 6G. The influence of hollow structure and $\mathrm{SiO}_{2}$ coating on SERS activity of $\mathrm{Fe}_{3} \mathrm{O}_{4}$ spheres will be clarified. Moreover, the reusability of the proposed hollow composite SERS substrates will also be studied.

\section{Experimental procedures}

\subsection{Sample preparation}

Hollow iron oxide spheres were prepared using the spray pyrolysis method. Iron (II) chloride $\left(\mathrm{FeCl}_{2}\right.$, anhydrous, $99.5 \%$ (metals basis), Alfa
Aesar) and Iron (III) chloride ( $\mathrm{FeCl}_{3}$, anhydrous, 98\%, Alfa Aesar) were used as precursors, and de-ionized water was the solvent. Glycine (GN, $\mathrm{C}_{2} \mathrm{H}_{5} \mathrm{NO}_{2}, 98 \%$, Acros Organics) was added to obtain hollow structures. $0.1 \mathrm{M}$ solution was atomized into small droplets using an atomizer (nebulizer, King Ultrasonics Co., Ltd, Taipei, Taiwan) and then sequentially underwent solvent evaporation, solute precipitation and precursor decomposition in the heated tubular reactor at $550{ }^{\circ} \mathrm{C}$ in ambient atmosphere. Iron oxide spheres thus formed were collected using a cylindrical electrostatic collector with high voltage potential. A post annealing was performed in $\mathrm{Ar} / \mathrm{H}_{2}$ or $\mathrm{N}_{2} / \mathrm{H}_{2}$ atmosphere at $350{ }^{\circ} \mathrm{C}$. Using TEOS (Tetraethoxysilane, $\mathrm{SiC}_{8} \mathrm{H}_{20} \mathrm{O}_{4}$ ) as the starting material, $\mathrm{SiO}_{2}$ shell was then coated on the iron oxide spheres by sol-gel method. Silver nanoparticles were then deposited on the sphere surface via the incipient wetness method. Silver nitrate $\left(\mathrm{AgNO}_{3}\right)$ was the raw material.

\subsection{Material characterization}

All the samples were characterized by X-ray Diffractometer (XRD) with $\mathrm{Cu} \mathrm{K}$ radiation (Bruker D2 PHASER). Their morphologies were observed using scanning electron microscope (SEM, JEOL JSM-6500F) and transmission electron microscope (TEM, JEOL JEM-2100F). The oxide spheres were sectioned using ultramicrotomy (LEICA ULTRACUT UC7). The practice is described in detail elsewhere [20]. Cs corrected STEM (JEOL JEM-ARM200F), operated at $200 \mathrm{kV}$ and equipped with electron energy loss spectroscopy (EELS), was applied for phase identification. X-ray absorption measurements were carried out at National Synchrotron Radiation Research Center (NSRRC) in Taiwan. The X-ray absorption near edge fine structures (XANES) spectra at the $\mathrm{Ag} K$-edge was recorded at HSGM beam line $01 \mathrm{C}$ and the energy resolution was set to $1.25 \mathrm{eV}$. Raman scattering was performed with a spectrometer equipped with a micro Raman system (HORIBA iHR550) and a diode laser at an excitation wavelength of $532 \mathrm{~nm}$. The magnetization was measured at room temperature using a vibrating sample magnetometer (VSM).
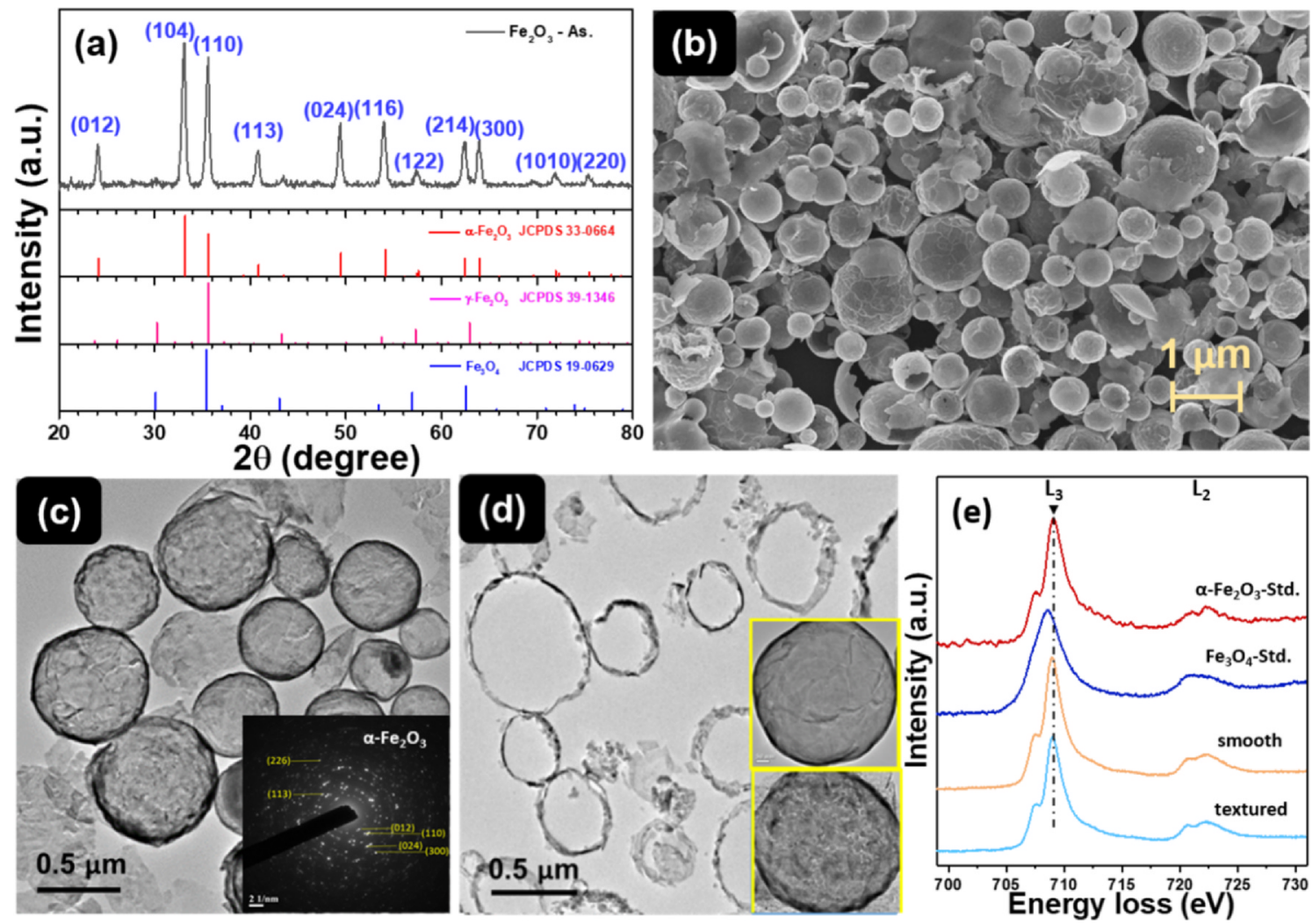

Fig. 2. (a) XRD and (b) SEM, (c) TEM, (d) cross sectional TEM results, and (e) EELS analysis of iron oxide spheres prepared by spray pyrolysis method. 


\subsection{Experimental results and discussion}

\section{Characteristics of iron oxide hollow spheres}

The phase of iron oxide spherical particles was determined by X-ray diffraction analysis (Fig. 2(a)). Characteristic diffraction peaks agree with standard $\alpha-\mathrm{Fe}_{2} \mathrm{O}_{3}$ (JCPDS-0690629). The diffraction peaks verify that the as-synthesized spheres were well-crystalline $\alpha-\mathrm{Fe}_{2} \mathrm{O}_{3}$. No other phases could be detected. SEM micrographs given in Fig. 2 (b) clearly show that the spheres are with uniform shape, and the sphere size ranged from $300 \mathrm{~nm}$ to $1.2 \mu \mathrm{m}$. TEM image and corresponding inserted selected-area electron diffraction (SAED) pattern (Fig. 2 (c)) again demonstrate the as-synthesized spheres were $\alpha-\mathrm{Fe}_{2} \mathrm{O}_{3}$. The cross-sectional TEM images (Fig. 2(d)) indicate that those $\alpha-\mathrm{Fe}_{2} \mathrm{O}_{3}$ spheres were with continuous and uniform shell, of which the thickness was between 15 and $30 \mathrm{~nm}$. Notably, two kinds of the shell appearance can be distinguished, i.e. one with smooth surface and the other one with textured patterns.

EELS analysis was performed to examine the differences between these two kinds of iron oxide shells (Fig. 2(e)). For ferric and ferrous oxides $\left(\mathrm{Fe}_{2} \mathrm{O}_{3}\right.$ and $\mathrm{FeO}$ ), the EELS $\mathrm{Fe} L_{2,3}$ edges can be primarily described as transitions from a ground state, Fe $2 p^{6} 3 d^{5}\left(2 p^{6} 3 d^{6}\right)$ to a final excited state, $\mathrm{Fe} 2 p^{5} 3 d^{6}\left(2 p^{5} 3 d^{7}\right)$, respectively. $\mathrm{Fe}_{2} \mathrm{O}_{3}$ to $\mathrm{FeO}$ can thus be differentiated and the $\mathrm{Fe} L$ edge of the iron oxide spheres are plotted in Fig. 2 (e) along with hematite and magnetite reference spectra. The energy loss near edge spectrum (ELNES) of the $L_{3}$ edge show a clear shoulder at $708 \mathrm{eV}$, with a maximum located at $710 \mathrm{eV}$. The spectra obtained from both types of hollow sphere shells (smooth and textures) are found to be the same as the given $\alpha-\mathrm{Fe}_{2} \mathrm{O}_{3}$ reference $[21,22]$.

It is expected that $\mathrm{Fe}_{3} \mathrm{O}_{4}$ possesses a larger magnetization than other iron oxides [23]. Accordingly, the as-synthesized $\alpha-\mathrm{Fe}_{2} \mathrm{O}_{3}$ hollow spheres need to be annealed in various reducing atmospheres for phase transformation. As tabulated in Table 1, samples I, II and III represent iron oxide hollow spheres subjected to post annealing in $\mathrm{Ar}+\mathrm{H}_{2}$ at $350{ }^{\circ} \mathrm{C}$ for $1 \mathrm{~h}$, in $\mathrm{Ar}+\mathrm{H}_{2}$ at $350{ }^{\circ} \mathrm{C}$ for $2 \mathrm{~h}$, and in $\mathrm{N}_{2}+\mathrm{H}_{2}$ at $400{ }^{\circ} \mathrm{C}$ for $1 \mathrm{~h}$, respectively. The morphology and phase identification of the sample I are shown in Fig. 3. SEM image (Fig. 3 (a)) and TEM crosssectional observation (Fig. 3(b)) again indicate the uniform shape and hollow structure of the iron oxide spheres subjected to reductive annealing. XRD analysis verifies that the oxide phase turns from $\alpha-\mathrm{Fe}_{2} \mathrm{O}_{3}$ to $\mathrm{Fe}_{3} \mathrm{O}_{4}$ or $\gamma-\mathrm{Fe}_{2} \mathrm{O}_{3}$ (Fig. 3(c)). However, it is difficult to distinguish $\mathrm{Fe}_{3} \mathrm{O}_{4}$ and $\gamma-\mathrm{Fe}_{2} \mathrm{O}_{3}$ from XRD patterns. Therefore, further EELS analytical results are given as follows.

It has been reported that $\mathrm{Fe}_{3} \mathrm{O}_{4}$ possesses a mixed valence state and the $L_{3}$ edge appears almost shapeless [24-26], while in the case of $\alpha$ $\mathrm{Fe}_{2} \mathrm{O}_{3}$ and $\gamma-\mathrm{Fe}_{2} \mathrm{O}_{3}$ which are with primary trivalent ground state, a visible splitting in the $L_{3}$ can be observed. EELS spectra given in Fig. 3(d) show that in the case of sample I, the Fe $L$ edge obtained from spheres with textured surface is consistent with that of the $\mathrm{Fe}_{3} \mathrm{O}_{4}$ standard. The ELNES of Fe $L$ edge obtained from spheres with smooth surface is relatively closer to a ferric edge and could thus be referred to $\gamma-\mathrm{Fe}_{2} \mathrm{O}_{3}$. Most of the hollow spheres could be confirmed as $\mathrm{Fe}_{3} \mathrm{O}_{4}$, and a minor portion of them were $\gamma-\mathrm{Fe}_{2} \mathrm{O}_{3}$. Post annealing at the same conditions ( $\mathrm{Ar}+\mathrm{H}_{2}$ at $350{ }^{\circ} \mathrm{C}$ ) but longer time (the sample II) brought about similar results (Fig. S1). $\mathrm{Fe}_{3} \mathrm{O}_{4}$ hollow spheres are the majority. In

Table 1

Designation of samples and their conditions.

\begin{tabular}{ll}
\hline Samples & Conditions \\
\hline I & Iron oxide hollow spheres annealed in $\mathrm{Ar}+\mathrm{H}_{2}$ at $350{ }^{\circ} \mathrm{C}$ for $1 \mathrm{~h}$ \\
II & Iron oxide hollow spheres annealed in $\mathrm{Ar}+\mathrm{H}_{2}$ at $350{ }^{\circ} \mathrm{C}$ for $2 \mathrm{~h}$ \\
III & Iron oxide hollow spheres annealed in $\mathrm{N}_{2}+\mathrm{H}_{2}$ at $400{ }^{\circ} \mathrm{C}$ for $1 \mathrm{~h}$ \\
IV & $\mathrm{Ag} @ \mathrm{SiO}_{2} @ \mathrm{Fe}_{3} \mathrm{O}_{4}$ hollow spheres with $\mathrm{Ag} / \mathrm{Fe}_{3} \mathrm{O}_{4}$ of 0.71 \\
V & $\mathrm{Ag} @ \mathrm{SiO}_{2} @ \mathrm{Fe}_{3} \mathrm{O}_{4}$ hollow spheres with $\mathrm{Ag} / \mathrm{Fe}_{3} \mathrm{O}_{4}$ of 0.83 \\
VI & $\mathrm{Ag} @ \mathrm{SiO}_{2} @ \mathrm{Fe}_{3} \mathrm{O}_{4}$ hollow spheres with $\mathrm{Ag} / \mathrm{Fe}_{3} \mathrm{O}_{4}$ of 0.91 \\
\hline
\end{tabular}

contrast, for $\alpha-\mathrm{Fe}_{2} \mathrm{O}_{3}$ hollow spheres annealed in $\mathrm{N}_{2}+\mathrm{H}_{2}$ (sample III), the major portion of the spheres were identified as $\gamma-\mathrm{Fe}_{2} \mathrm{O}_{3}$ rather than $\mathrm{Fe}_{3} \mathrm{O}_{4}$ (Fig. S2). This brings us to believe that annealing atmosphere affects the phase transformation of iron oxides.

The magnetization curves of hollow iron oxide spheres under different conditions were measured using VSM at room temperature, and the results are plotted in Fig. 4. In order to clarify the effect of hollow structures, the solid-cored $\mathrm{Fe}_{3} \mathrm{O}_{4}$ spheres with similar sizes was also prepared for comparison. Fig. 4 illustrates that as-synthesized hollow spheres $\left(\alpha-\mathrm{Fe}_{2} \mathrm{O}_{3}\right)$ exhibited a very weak magnetization hysteresis. The coercive field $\left(\mathrm{H}_{\mathrm{c}}\right)$ was 80 Oe and the saturation magnetization $\left(\mathrm{M}_{\mathrm{s}}\right)$ was only $10 \mathrm{emu} / \mathrm{g}$. If the saturation magnetization $\mathrm{M}_{\mathrm{s}}$ is concerned, the increasing order was hollow $\alpha-\mathrm{Fe}_{2} \mathrm{O}_{3}$, sample III $(71 \mathrm{emu} / \mathrm{g}$ ), solid cored $\mathrm{Fe}_{3} \mathrm{O}_{4}(73 \mathrm{emu} / \mathrm{g})$, sample II $(123 \mathrm{emu} / \mathrm{g})$ and then sample I $(130 \mathrm{emu} / \mathrm{g})$. With respect to coercive field $\left(\mathrm{H}_{\mathrm{c}}\right)$, the increasing order was $\alpha-\mathrm{Fe}_{2} \mathrm{O}_{3}$, sample III (150 Oe), solid cored $\mathrm{Fe}_{3} \mathrm{O}_{4}$ (165 Oe), sample II and then sample I (200 Oe). It is also noticeable that hollow $\mathrm{Fe}_{3} \mathrm{O}_{4}$ sphere, sample I and sample II, exhibited a tremendous coercive field $\mathrm{H}_{\mathrm{c}}$ of about 200 Oe, which was larger than most of the reported values (e.g. nanoparticle (80 Oe), bulk (20 Oe) and hollow spheres [15]). Moreover, samples I and II also possessed a high magnetic saturation (130 emu/g), which was overwhelmingly greater than those in literature (e.g. nanowires $(71 \mathrm{emu} / \mathrm{g})$ [27], nanopyramid $(52.5 \mathrm{emu} / \mathrm{g})$ [28], nanocubes (40 emu/g) [29], and nanospheres (31 emu/g [29] and $90 \mathrm{emu} / \mathrm{g}$ [30]), as well as nanoporous structures (95 emu/g) [31]).

To further understand the unique hysteresis behavior of $\mathrm{Fe}_{3} \mathrm{O}_{4}$ hollow spheres, the domain state was investigated through a Day plot analysis, where the $M_{\mathrm{rs}} / M_{\mathrm{s}}$ were plotted as a function of $H_{\mathrm{cr}} / H_{\mathrm{c}}$ [32]. $M_{r s}$ and $H_{c r}$ are the remanent magnetization and the remanent corrective field respectively, and can be determined experimentally following the method described by Ye et al. [15]. Based on these values, singledomain (SD), pseudosingle-domain (PSD), and multidomain (MD) states of magnetite can be distinguished $[33,34]$. Ye et al. showed that the Day plots for hollow magnetite spheres appeared in the PSD region, and shifted to the SD region when the temperature was down to $10 \mathrm{~K}$ or below [15]. In this study, the behavior of the hollow $\mathrm{Fe}_{3} \mathrm{O}_{4}$ spheres (sample I) was investigated. The value of $M_{r s}$ and $H_{c r}$ were determined according to the $\mathrm{M}-\mathrm{H}$ curve measurement under different applied magnetic field, as shown in Fig. S3. The values of $M_{\mathrm{rs}} / M_{\mathrm{s}}$ and $H_{\mathrm{cr}} / H_{\mathrm{c}}$ at $300 \mathrm{~K}$ were found to be 0.45 and 1.5 , respectively, indicating that despite their overall large size, sample I spheres approached the SD region even at $300 \mathrm{~K}$. This could be interpreted in terms of the formation of vortex and onion states theoretically predicted for hollow spheres of magnetically soft ferro-magnet $[15,35]$.

\section{Characteristics of $\mathrm{Ag} @ \mathrm{SiO}_{2} @ \mathrm{Fe}_{3} \mathrm{O}_{4}$ composite hollow spheres}

Considering that sample I possessed the highest magnetization, it was selected as the template to prepare SERS substrates. A thin $\mathrm{SiO}_{2}$ layer and $\mathrm{Ag}$ nanoparticles were deposited on sample I in sequence in order to protect isolate $\mathrm{Fe}_{3} \mathrm{O}_{4}$ and arise SERS effect respectively. TEM observations demonstrate that both concentration of TEOS and synthesis time affect the thickness of $\mathrm{SiO}_{2}$ layer (Fig. S4). A 12 nm-thick $\mathrm{SiO}_{2}$ layer was adopted hereafter, which was prepared using $0.4 \mathrm{M}$ TEOS with reaction time of $12 \mathrm{~h}$.

Through the control of the precursor concentration in the synthesis of $\mathrm{Ag}$ nanoparticles, the size as well as the distribution of Ag NPs can be determined. As also listed in Table 1 , the $\mathrm{Ag}$ to $\mathrm{Fe}_{3} \mathrm{O}_{4}$ mole ratio was set to be $0.71,0.83$, and 0.91 . The $\mathrm{Ag} @ \mathrm{SiO}_{2} @ \mathrm{Fe}_{3} \mathrm{O}_{4}$ composite spheres thus obtained were designated as the samples IV, V, and VI, respectively. Their morphologies are shown in Fig. 5 (a)(b)(c), and the TEM/ EDX mapping reveals the elemental distribution (Fig. S5). High resolution lattice image shown in Fig. 5 (d) verifies that the Ag nanoparticles were well crystalline and closely attached on the sphere surface. The lattice fringe spacing of $\mathrm{Ag}$ was measured to be $0.236 \mathrm{~nm}$ (red line in the inset), matching the $d$ values of the (111) planes of the FCC 

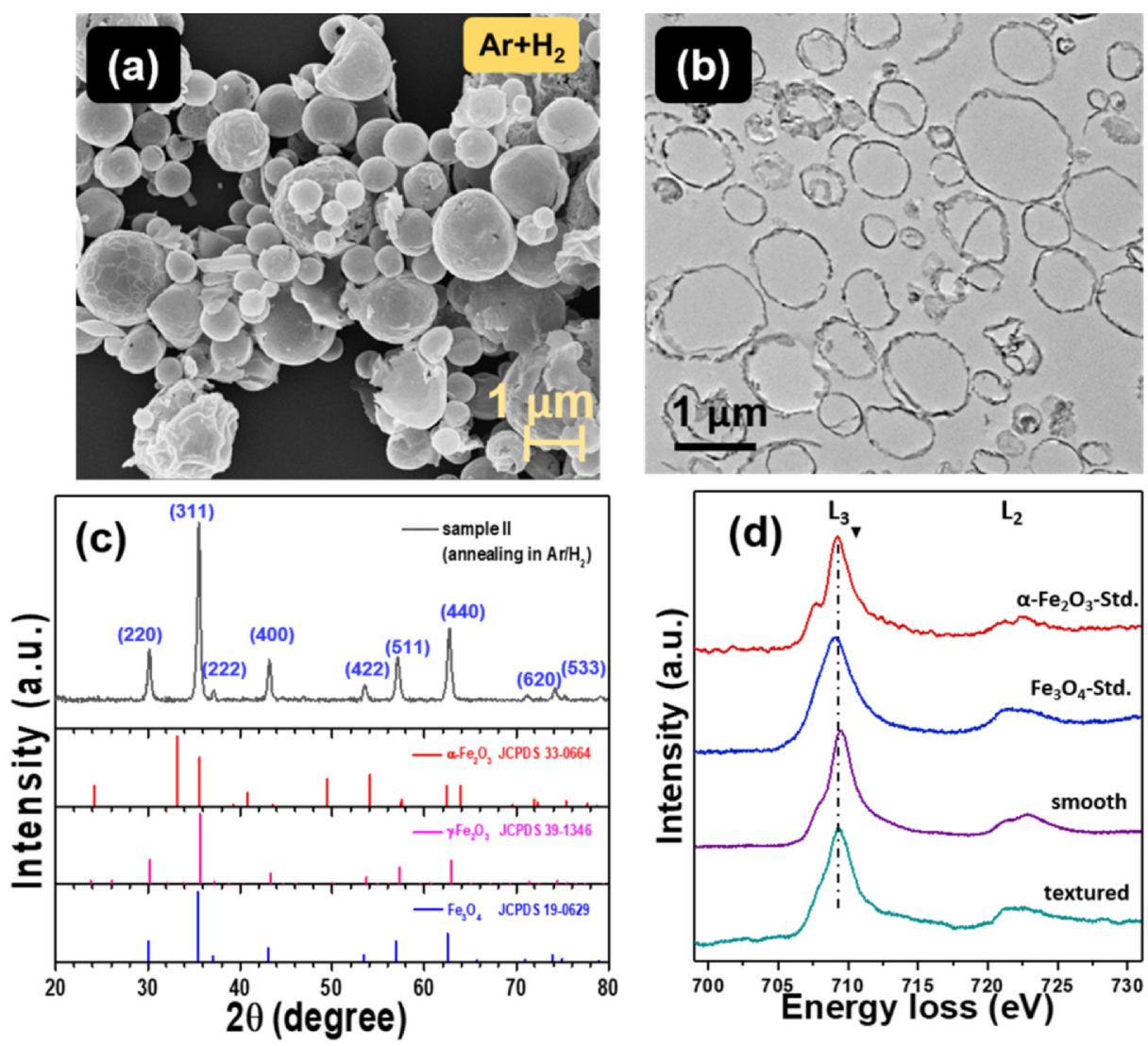

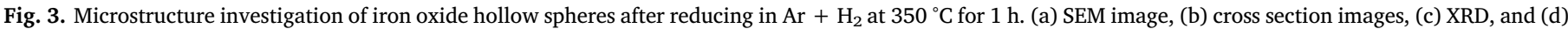
EELS spectrum and the standards.

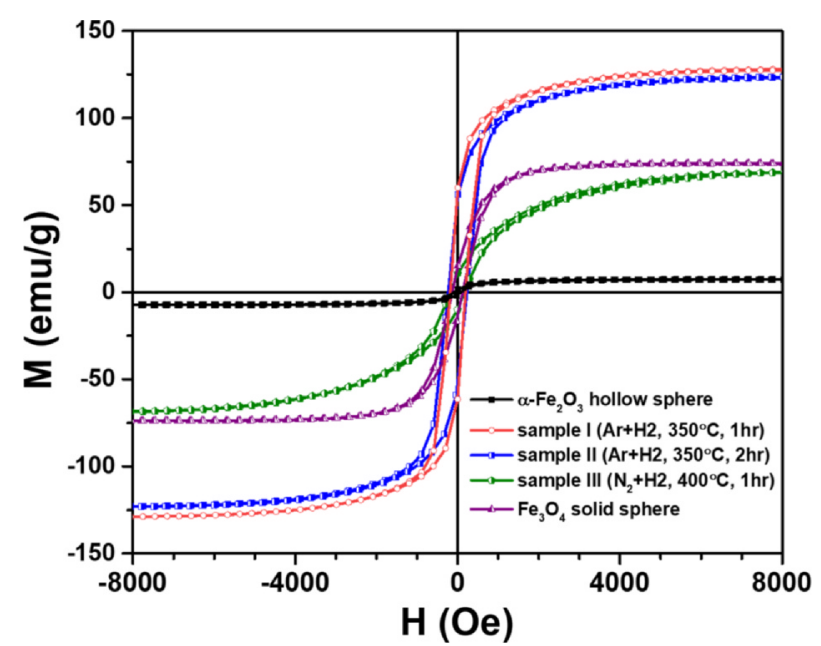

Fig. 4. Magnetic measurement of iron oxide hollow sphere of different phases.

Ag. For the samples IV, V, and VI, the silver particle diameter was $28 \mathrm{~nm}, 18 \mathrm{~nm}$, and $27 \mathrm{~nm}$, respectively, while the average Ag nanoparticles spacing was $22 \mathrm{~nm}, 10 \mathrm{~nm}$, and $11 \mathrm{~nm}$. This suggests that sample $\mathrm{V}$ possessed the smallest and closest $\mathrm{Ag}$ nanoparticles on oxide sphere surface.

The electronic structure of cations was further investigated by EELS and XAS. ELNES of Fe $L$ edge (Fig. 5(e)) and XANES of Fe $K$ edge (Fig. 5(f)) obtained from sample $\mathrm{V}$ both imply that the iron oxide was not pure $\mathrm{Fe}_{3} \mathrm{O}_{4}$ after the chemical synthesis of $\mathrm{Ag}$ nanoparticles. In Fig. 5 (e), the shoulder on the peak in low energy side might result from partial oxidization of $\mathrm{Fe}_{3} \mathrm{O}_{4}$ to $\gamma-\mathrm{Fe}_{2} \mathrm{O}_{3}$. In Fig. 5 (f), the shift of edge to high energy side also indicates the presence of $\gamma-\mathrm{Fe}_{2} \mathrm{O}_{3}$ [36]. The
XANES of $\mathrm{Ag} L$ edges from the Ag nanoparticles of samples $\mathrm{V}$ and the standard spectrum are shown in Fig. 5(g). The configuration of $\mathrm{Ag}$ metal is $\mathrm{d}^{10} \mathrm{~s}^{1}$ and the $\mathrm{Ag} L$ edge intensity has been reported to be sensitive to the charge transfer that modulates the filling of $d$ and $s$ bands. With respect to pure Ag, three weak peaks respectively located 2.0, 5.2, and $8.8 \mathrm{eV}$ above the threshold (around $3350 \mathrm{eV}$ ) could be observed, which have been assigned to $2 p \rightarrow s$ band transitions [37]. As seen in Fig. 5 (g), the fine structures of Ag spectra detected from Ag@ $\mathrm{SiO}_{2} @ \mathrm{Fe}_{3} \mathrm{O}_{4}$ hollow composite sphere and bare Ag NPs were identical. This doesn't agreed to the cases of $\mathrm{Ag} @ \mathrm{CeO}_{2}$ [38] and Au-Ag alloys [39], where an increase in the $\mathrm{d}$ band population of $\mathrm{Ag}$ was observed due to charge transfer. Above spectroscopic investigations of sample $\mathrm{V}$ indicate that the covering of $\mathrm{SiO}_{2}$ layer could prevent charge transfer between $\mathrm{Ag}$ nanoparticles and oxide layer, though partial oxidization of $\mathrm{Fe}_{3} \mathrm{O}_{4}$ was still observed. On the other hand, $\mathrm{Ag} @ \mathrm{Fe}_{3} \mathrm{O}_{4}$ hollow composites without a $\mathrm{SiO}_{2}$ barrier layer, a slightly shift of $\mathrm{Fe} K$ edge (Fig. S6 (a)) and a noticeable increase of the $\mathrm{Ag} L$ edge intensity was shown, as indicated in red arrows in Fig. S6 (b), implying that both the degree of oxidization of $\mathrm{Fe}_{3} \mathrm{O}_{4}$ and the charge transfer between $\mathrm{Ag}$ and $\mathrm{Fe}_{3} \mathrm{O}_{4}$ were stronger without the cover of $\mathrm{SiO}_{2}$ layer.

\section{Performance of the Ag@SiO ${ }_{2} @ \mathrm{Fe}_{3} \mathrm{O}_{4}$ hollow composite spheres}

The $\mathrm{M}-\mathrm{H}$ curves of $\mathrm{Fe}_{3} \mathrm{O}_{4}$ based hollow composite spheres are given in Fig. 6. The saturation magnetization of $\mathrm{Ag} @ \mathrm{SiO}_{2} @ \mathrm{Fe}_{3} \mathrm{O}_{4}$ hollow composite spheres were quite similar, in a decreasing order they are sample V, sample VI, and then sample IV. All of them possessed the $\mathrm{M}_{\mathrm{s}}$ greater than the one without $\mathrm{SiO}_{2}$ coating (hollow $\mathrm{Ag} @ \mathrm{Fe}_{3} \mathrm{O}_{4}$ in Fig. 6), but apparently lower than those with bare hollow $\mathrm{Fe}_{3} \mathrm{O}_{4}$ spheres (samples I, II, and III in Fig. 4). The degradation in $\mathrm{M}_{\mathrm{s}}$ for composite spheres can be attributed to the attachment of nonmagnetic Ag nanoparticle and amorphous $\mathrm{SiO}_{2}$ as well, thereby a significant reduction of 

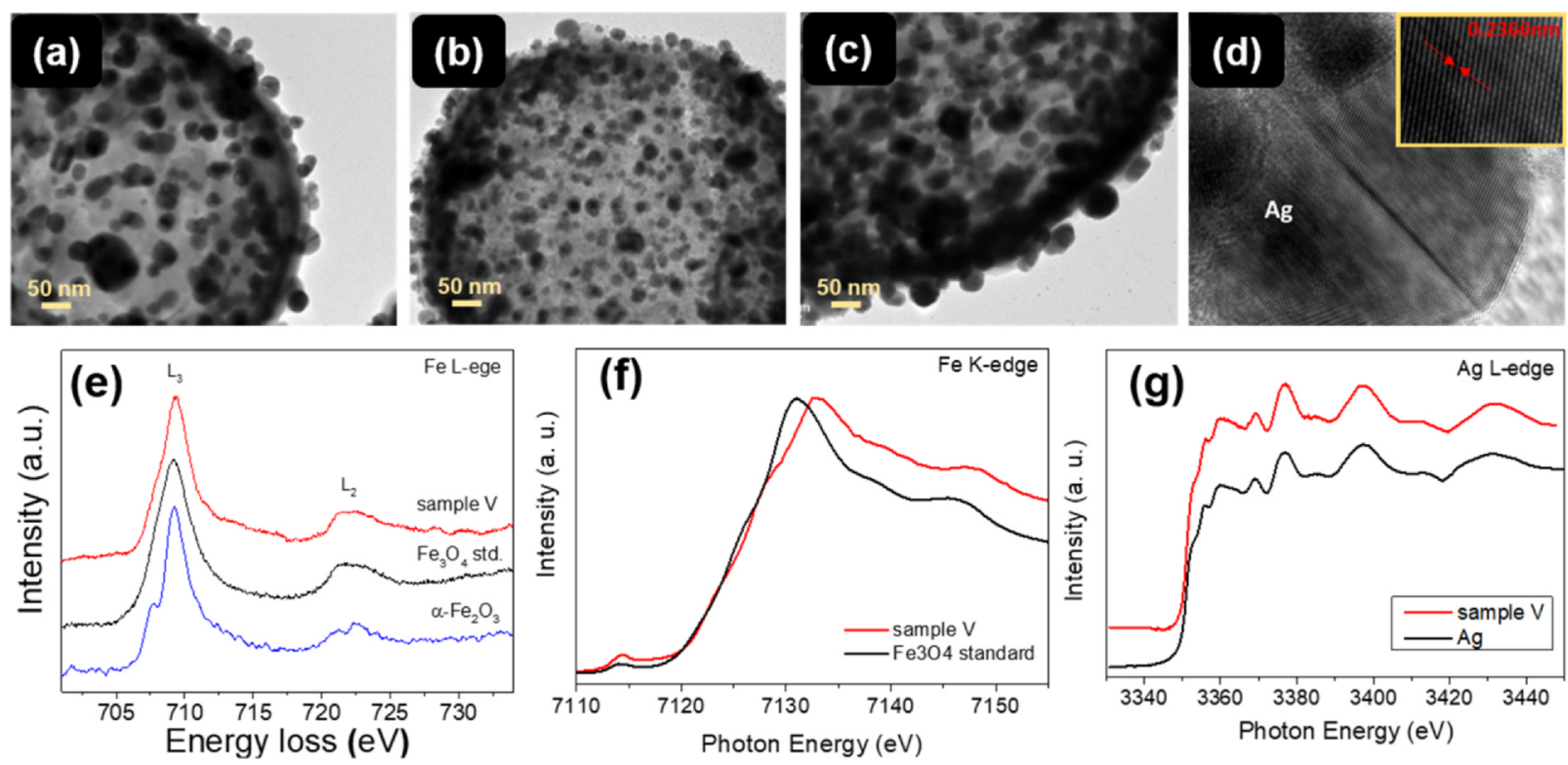

Fig. 5. TEM results of $\mathrm{Ag} @ \mathrm{SiO}_{2} @ \mathrm{Fe}_{3} \mathrm{O}_{4}$ hollow sphere composites with different content of Ag (a) sample IV, (b) sample V, and (c) sample VI. (d) HRTEM of Ag NPs on the surface of sample V. (e) EELS analysis of Fe $L$ edge. (f) Fe $K$ edge and (g) $\mathrm{Ag} L$ edge of the iron oxide sphere after Ag deposition.

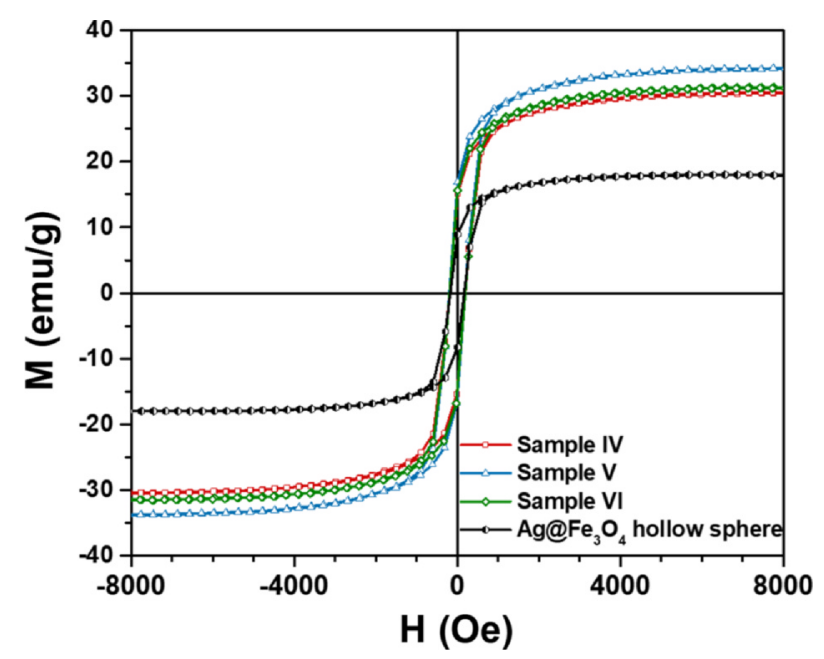

Fig. 6. Magnetic measurement of $\mathrm{Ag} @ \mathrm{SiO}_{2} @ \mathrm{Fe}_{3} \mathrm{O}_{4}$ hollow sphere with different amounts of Ag. The $\mathrm{M}-\mathrm{H}$ curve of $\mathrm{H}-\mathrm{Fe}_{3} \mathrm{O}_{4} @ \mathrm{Ag}$ was also plotted.

iron oxide weight fraction. In addition, the partial oxidization of $\mathrm{Fe}_{3} \mathrm{O}_{4}$ to $\gamma-\mathrm{Fe}_{2} \mathrm{O}_{3}$ in the preparation of $\mathrm{Ag}$ nanoparticles, as demonstrated by EELS analysis, also leads to the weakening of saturation magnetization. The $\mathrm{M}_{\mathrm{s}}$ values for present $\mathrm{Ag} @ \mathrm{SiO}_{2} @ \mathrm{Fe}_{3} \mathrm{O}_{4}$ hollow composite spheres composite are comparable to the recently reported nanoparticle based magnetic composites (e.g. Ag@ $\mathrm{SiO}_{2} @ \mathrm{Fe}_{3} \mathrm{O}_{4} \mathrm{NPs}$ or $\mathrm{Ag} @ \mathrm{C} @ \mathrm{Fe}_{3} \mathrm{O}_{4} \mathrm{NPs}$ ), which ranges from 30 to $35 \mathrm{emu} / \mathrm{g}[40,41]$.

To evaluate the SERS effect, $\mathrm{Ag} @ \mathrm{SiO}_{2} @ \mathrm{Fe}_{3} \mathrm{O}_{4}$ hollow composite spheres were used to detect typical analyte Rhodamine 6G (R6G), of which the concentration was set to be $1 \times 10^{-6} \mathrm{M}$. Ag@ $@ \mathrm{SiO}_{2} @ \mathrm{Fe}_{3} \mathrm{O}_{4}$ composite spheres with $\mathrm{Fe}_{3} \mathrm{O}_{4}$ solid core were also used for comparison. The SERS spectra of hollow composite spheres are illustrated in Fig. 7 (a), indicating Raman peaks at 1310, 1363, 1509, 1572 and $1650 \mathrm{~cm}^{-1}$, which could be accordance with the reported values. As for hollow composite spheres, sample $\mathrm{V}$ presented the most remarkable Raman signals. This can be referred to the combined effects of Ag nanoparticles spacing and size on SERS performance [33]. The signal intensity was stronger than the other two hollow composite spheres, as well as the solid ones. Take the Raman peak at $1650 \mathrm{~cm}^{-1}$ as example, it can be found that the signal intensity of sample $\mathrm{V}$ was 2.65 times greater than that of sold composite spheres.

The ability to form well suspension of those hollow SERS spherical substrate can be demonstrated in Fig. 7(b). The dispersion of Ag@ $\mathrm{SiO}_{2} @ \mathrm{Fe}_{3} \mathrm{O}_{4}$ hollow composite spheres in water (indicated by "H") was much better than those with solid core (indicated by "S"), which settled down much faster than the hollow ones. It is interesting that when a magnetic field was applied (the right bottle in Fig. 7(c) and the magnet was placed on the right side), the $\mathrm{Ag} @ \mathrm{SiO}_{2} @ \mathrm{Fe}_{3} \mathrm{O}_{4}$ hollow composite spheres can be immediately gathered, and completely separated from the solution within only $10 \mathrm{~s}$. The above results suggest that the developed magnetic hollow composite spheres realize well suspension and rapid separation, which can effectively enhance SERS performance. The magnetically concentrated sample $\mathrm{V}$ possessed $1650 \mathrm{~cm}^{-1}$ centered Raman peak with the signal intensity around 1.5 times higher than sample $\mathrm{V}$ without applying magnetic force, and 3.87 time greater than those with solid cores. The superior SERS performance of hollow sphere sample (e.g. sample V) than the solid spheres can be axcribed to following reasons. Solid spheres and hollow spheres with the same weight were adopted in SERS test, thereby the number of hollow spheres will be greater and thus a higher surface area as well as more Ag nanoparticles on the sphere surface, resulting in better SERS performance. In addition, the buoyancy resulted from hollow structure made the hollow spheres possessed better suspension ability in the solution and thus higher likelihood to react with analytes.

To evaluate reusability of the $\mathrm{Ag} @ \mathrm{SiO}_{2} @ \mathrm{Fe}_{3} \mathrm{O}_{4}$ hollow composite spheres, the same composites were used to detect again and again. After each measurement, the composites were cleaned with ethanol to remove residual molecules and ions, and separated using an external magnetic field. The renewed composites were then collected for next SERS detection. Fig. 8 shows the recycling test for SERS detection using sample V. Two different dye molecules, R6G and MB (methylene blue), were adopted in the recycling tests. After each detection, the composite was cleaned in ethanol and collected. As shown in Fig. 8 (a) and (b), SERS measurements were also performed every time the sphere substrates were reacted with the analytes (blue spectra) to evaluate the recycling feasibility, and performed when the substrates were just washed before next detection (red spectra) to examine dye molecule residues. It could be found that there were residual dye molecules detected, but the amount was quite limited (the intensity was 100 times less than that before cleaning), and did not affect next recycling test. Remarkably, after eight cycles, it still retained high SERS sensitivity for 


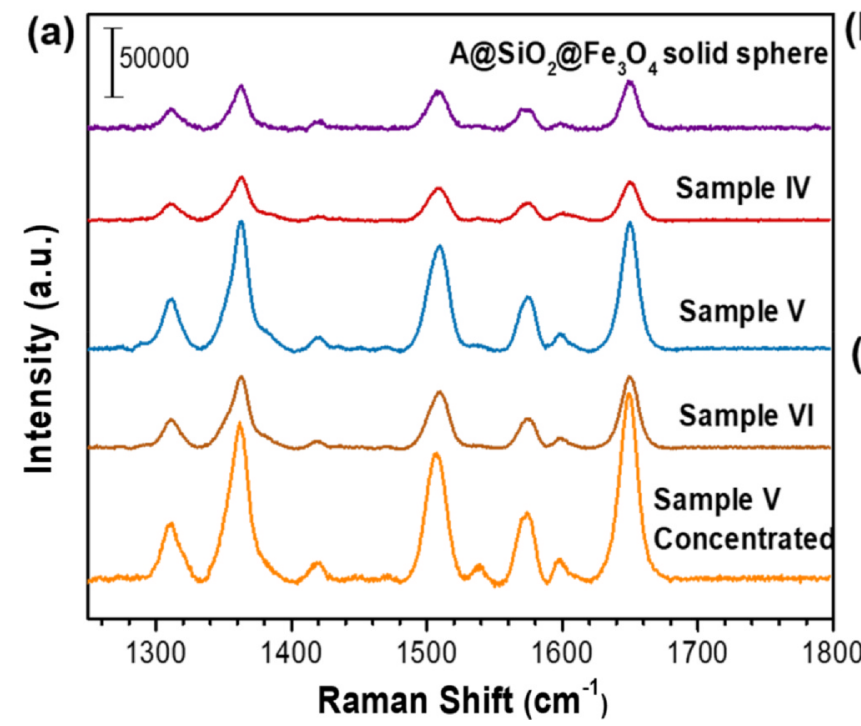

(b)

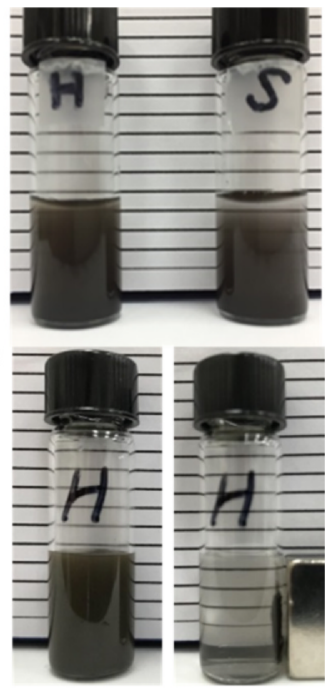

Fig. 7. (a) SERS results of Ag@SiO $2 @ \mathrm{Fe}_{3} \mathrm{O}_{4}$ hollow sphere composites with different amount of Ag NPs on the surface. (b) Comparison of the suspension in solution between hollow sphere and solid sphere. (c) Illustration of concentration of hollow spheres under external magnetic field.

R6G and MB, and realized reusability. The decrease in the Raman intensity might be attributed to the detachment of Ag nanoparticles from oxide sphere surface during the cleaning process, which was demonstrated by UV-vis spectral analysis (Fig. S7), where the absorption of Ag nanoparticles gradually decreases with increasing recycling numbers.

\section{Conclusions}

This study proposed and successfully developed $\mathrm{Ag} @ \mathrm{SiO}_{2} @ \mathrm{Fe}_{3} \mathrm{O}_{4}$ hollow composite spheres exhibiting excellent ferromagnetism and high SERS activity. $\mathrm{Fe}_{3} \mathrm{O}_{4}$ hollow microspheres were synthesized a massproduction method, spray pyrolysis, and subsequent post annealing to achieve $\alpha-\mathrm{Fe}_{2} \mathrm{O}_{3}$ to $\mathrm{Fe}_{3} \mathrm{O}_{4}$ transformation. The saturation magnetization of the $\mathrm{Fe}_{3} \mathrm{O}_{4}$ hollow microspheres can be up to $130 \mathrm{emu} / \mathrm{g}$ at $300 \mathrm{~K}$, which was much higher than the reported values. With a protective $\mathrm{SiO}_{2}$ coating and $\mathrm{Ag}$ nanoparticles providing localized surface plasmon resonance, it has been demonstrated that $\mathrm{Ag} @ \mathrm{SiO}_{2} @ \mathrm{Fe}_{3} \mathrm{O}_{4}$ hollow composite spheres can be well suspended and manipulated with the application of an external magnetic field. Both these two characteristics effectively enhance SERS performance. The reusability of the hollow composite SERS substrates was also demonstrated. The SERS signals were still distinguishable even in the 8 th test.

\section{CRediT authorship contribution statement}

Yu-Fang Huang: Formal analysis, Validation. Wen-Chi Huang: Formal analysis, Validation. Pei-Kai Hsu: Formal analysis, Validation. Jenn-Ming Song: Conceptualization, Investigation, Resources, Writing - review \& editing. Alexandre Gloter: Methodology, Resources, Writing - review \& editing. Shih-Yun Chen: Investigation, Conceptualization, Formal analysis, Writing - original draft, Writing review \& editing, Supervision, Funding acquisition, Project administration.

\section{Declaration of Competing Interest}

None.
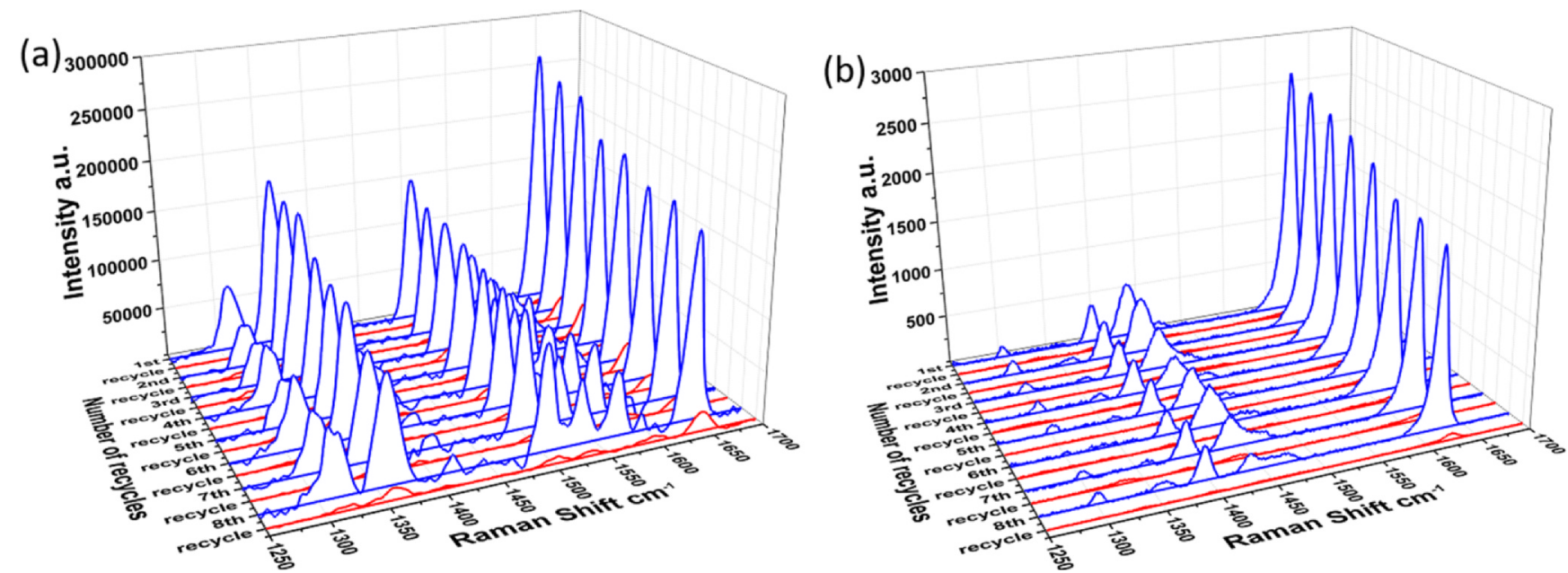

Fig. 8. SERS spectra of the reproducible measurements for the $\mathrm{Ag} @ \mathrm{SiO}_{2} @ \mathrm{Fe}_{3} \mathrm{O}_{4}$ hollow sphere substrate (sample V). Blue spectra were detected when the sphere substrates were reacted with the analytes, and red spectra were measured when the substrates were just cleaned by ethanol between two recycling tests. Two different dyes were used: (a) R6G and (b) MB. The concentration was $10^{-6} \mathrm{M}$. (For interpretation of the references to colour in this figure legend, the reader is referred to the web version of this article.) 


\section{Acknowledgement}

This research is supported by the Ministry of Science and Technology, Taiwan, Republic of China, under Contract No. MOST 1072112-M-011 -002 -MY3. We would also like to give special thanks to Dr. Shen-Chuan Lo from Industrial Technology Research Institute, Taiwan for provision of scanning electron microscope and transmission electron microscope.

\section{References}

[1] J. Du, C. Jing, Preparation of Thiol Modified $\mathrm{Fe}_{3} \mathrm{O}_{4} @ \mathrm{Ag}$ Magnetic SERS Probe for PAHs Detection and Identification, J. Phys. Chem. C 115 (36) (2011) 17829-17835.

[2] R.A. Halvorson, P.J. Vikesland, Surface-Enhanced Raman Spectroscopy (SERS) for Environmental Analyses, Environ. Sci. Technol. 44 (20) (2010) 7749-7755.

[3] A.M. Schwartzberg, J.Z. Zhang, Novel Optical Properties and Emerging Applications of Metal Nanostructures, J. Phys. Chem. C 112 (28) (2008) 10323-10337.

[4] J. Du, C. Jing, Preparation of Fe3O4@Ag SERS substrate and its application in environmental Cr(VI) analysis, J. Colloid Interface Sci. 358 (1) (2011) 54-61.

[5] K. Kim, H.J. Jang, K.S. Shin, Agnanostructures assembled on magnetic particles for ready SERS-based detection of dissolved chemical species, Analyst 134 (2) (2009) 308-313.

[6] X. Zhang, C. Niu, Y. Wang, S. Zhou, J. Liu, Gel-limited synthesis of dumbbell-like $\mathrm{Fe}_{3} \mathrm{O}_{4}-\mathrm{Ag}$ composite microspheres and their SERS applications, Nanoscale 6 (21) (2014) 12618-12625.

[7] C. Fan, S. Zhu, H. Xin, Y. Tian, E. Liang, Tunable and enhanced SERS activity of magneto-plasmonic $\mathrm{Ag}-\mathrm{Fe}_{3} \mathrm{O}_{4}$ nanocomposites with one pot synthesize method, J. Opt. 19 (1) (2017) 015401.

[8] M. Mandal, S. Kundu, S.K. Ghosh, S. Panigrahi, T.K. Sau, S.M. Yusuf, T. Pal, Magnetite nanoparticles with tunable gold or silver shell, J. Colloid Interface Sci. 286 (1) (2005) 187-194.

[9] Z. Xu, Y. Hou, S. Sun, Magnetic Core/Shell $\mathrm{Fe}_{3} \mathrm{O}_{4} / \mathrm{Au}$ and $\mathrm{Fe}_{3} \mathrm{O}_{4} / \mathrm{Au} / \mathrm{Ag}$ Nanoparticles with Tunable Plasmonic Properties, J. Am. Chem. Soc. 129 (28) (2007) 8698-8699.

[10] Z. Rostami, M. Rouhanizadeh, N. Nami, D. Zareyee, Fe3O4 magnetic nanoparticles (MNPs) as an effective catalyst for synthesis of indole derivatives, Nanochem. Res. 3 (2) (2018) 142-148.

[11] V.L. Schmit, R. Martoglio, B. Scott, A.D. Strickland, K.T. Carron, Lab-on-a-Bubble: Synthesis, Characterization, and Evaluation of Buoyant Gold Nanoparticle-Coated Silica Spheres, J. Am. Chem. Soc. 134 (1) (2012) 59-62.

[12] D. Sarkar, M. Mandal, K. Mandal, Domain controlled magnetic and electric properties of variable sized magnetite nano-hollow spheres, J. Appl. Phys. 112 (6) (2012) 064318.

[13] Q. Huang, L. Zou, D. Chen, Phase and morphology controlled in the synthesis of iron oxide particles: dimension-based carbonaceous materials as modifiers, RSC Adv. 6 (85) (2016) 82294-82297.

[14] D.T. Nguyen, K.S. Kim, Functionalization of magnetic nanoparticles for biomedical applications, Korean J. Chem. Eng. 31 (8) (2014) 1289-1305.

[15] Q.L. Ye, Y. Kozuka, H. Yoshikawa, K. Awaga, S. Bandow, S. Iijima, Effects of the unique shape of submicron magnetite hollow spheres on magnetic properties and domain states, Phys. Rev. B 75 (2007) 224404.

[16] Q.L. Ye, H. Yoshikawa, K. Awaga, Magnetic and Optical Properties of SubmicronSize Hollow Spheres, Materials 3 (2) (2010) 1244-1268.

[17] O.N. Shebanova, P. Lazor, Raman study of magnetite (Fe3O4): laser-induced thermal effects and oxidation, J. Raman Spectrosc. 34 (2003) 845-852.

[18] F.X. Liu, Y. Xiao, Y.S. Li, Silica-supported silver nano-particles for surface-enhanced Raman spectroscopy, J. Raman Spectrosc. 32 (2001) 73-77.

[19] K. Kim, H.S. Kim, H.K. Park, Facile Method To Prepare Surface-Enhanced-Raman-
Scattering-Active Ag Nanostructures on Silica Spheres, Langmuir 22 (2006) 8083-8088.

[20] Dr. R. Godehardt ć Dr. R. Adhikari ċ Dr. G.-M. Kim, Dr. S. Henning ċ DP V. Seydewitz ć DP W. Lebek “Electron Microscopy of Polymers", pp 199-217, 2008 Springer-Verlag Berlin Heidelberg.

[21] S. Czekaj, F. Nolting, L.J. Heyderman, P.R. Willmott, G. van der Laan, Sign dependence of the $\mathrm{x}$-ray magnetic linear dichroism on the antiferromagnetic spin axis in LaFeO3 thin films, Phys. Rev. B 73 (2) (2006) 020401.

[22] A. Gloter, A. Douiri, M. Tencé, C. Colliex, Improving energy resolution of EELS spectra: an alternative to the monochromator solution, Ultramicroscopy 96 (3-4) (2003) 385-400.

[23] K. Buyukhatipoglu Æ A. Morss Clyne, "Controlled flame synthesis of $\alpha$-Fe2O3 and Fe3O4 nanoparticles: effect of flame configuration, flame temperature, and additive loading", J. Nanopart. Res. 12 (2010) 1495-1508.

[24] L. Štichauer, A. Mirone, S. Turchini, T. Prosperi, S. Zennaro, N. Zema, C. Bonningue, X-ray absorption spectroscopy and magnetic circular dichroism of the Mn-ferrite nanocrystalline thin films, J. Appl. Phys. 90 (5) (2001) 2511-2516.

[25] M. Sacchi, C.F. Hague, S. Gota, E. Guiot, M. Gautier-Soyer, L. Pasquali, J.H. Underwood, Resonant scattering of polarized soft X-rays for the study of magnetic oxide layers, J. Electron Spectrosc. Relat. Phenom. 101 (1999) 407-412.

[26] J. Chen, D.J. Huang, A. Tanaka, C.F. Chang, S.C. Chung, W.B. Wu, C.T. Chen, Magnetic circular dichroism in Fe $2 \mathrm{p}$ resonant photoemission of magnetite, Phys. Rev. B 69 (8) (2004) 085107.

[27] J. Wang, Q. Chen, C. Zeng, B. Hou, Magnetic-Field-Induced Growth of SingleCrystalline $\mathrm{Fe}_{3} \mathrm{O}_{4}$ Nanowires, Adv. Mater. 16 (2) (2004) 137-140.

[28] F. Liu, P.J. Cao, H.R. Zhang, J.F. Tian, C.W. Xiao, C.M. Shen, J.Q. Li, H.J. Gao, Novel Nanopyramid Arrays of Magnetite, Adv. Mater. 17 (15) (2005) 1893-1897.

[29] G. Zhen, B.W. Muir, B.A. Moffat, P. Harbour, K.S. Murray, B. Moubaraki, P. Mulvaney, Comparative Study of the Magnetic Behavior of Spherical and Cubic Superparamagnetic Iron Oxide Nanoparticles, J. Phys. Chem. C 115 (2) (2010) 327-334

[30] Q. Li, C.W. Kartikowati, S. Horie, T. Ogi, T. Iwaki, K. Okuyama, Correlation between particle size/domain structure and magnetic properties of highly crystalline $\mathrm{Fe}_{3} \mathrm{O}_{4}$ nanoparticles, Sci. Rep. 7 (1) (2017) 9894.

[31] L. Zhao, H. Zhang, Y. Xing, S. Song, S. Yu, W. Shi, X. Guo, J. Yang, Y. Lei, F. Cao, Morphology-Controlled Synthesis of Magnetites with Nanoporous Structures and Excellent Magnetic Properties, Chem. Mater. 20 (1) (2007) 198-204.

[32] Ö. Özdemir, D.J. Dunlop, B.M. Moskowitz, Changes in remanence, coercivity and domain state at low temperature in magnetite, Earth Planet. Sci. Lett. 194 (3-4) (2002) 343-358.

[33] David J. Dunlop, Theory and application of the Day plot (Mrs/Ms versus Hcr/Hc), J. Geophys. Res. 107 (B3) (2002) 2056, https://doi.org/10.1029/2001JB000486.

[34] R.J. Enkin, J. Baker, D. Nourgaliev, P. Iassonov, T.S. Hamilton, Magnetic hysteresis parameters and Day plot analysis to characterize diagenetic alteration in gas hydrate-bearing sediments, J. Geophys. Res., Vol. 112, B06S90, doi:10.1029/ 2006JB004638, 2007

[35] M.I. Sloika, D.D. Sheka, V.P. Kravchuk, O.V. Pylypovskyi, Y. Gaididei, Geometry induced phase transitions in magnetic spherical shell, J. Magn. Magn. Mater. 443 (2017) 404-412.

[36] C. Piquer, M.A. Laguna-Marco, A.G. Roca, R. Boada, C. Guglieri, J. Chaboy, Fe KEdge X-ray Absorption Spectroscopy Study of Nanosized Nominal Magnetite, J. Phys. Chem. C 118 (2) (2014) 1332-1346.

[37] A. Bzowski, T.K. Sham, Y.M. Yiu, Ag L-edge x-ray-absorption near-edge-structure study of charge redistribution at the Ag site in Au-Ag alloys, Phys Rev B 15:49(19):13776-13779 (1994).

[38] E.N. Tseng, Y.T. Hsiao, Y.C. Chen, S.Y. Chen, A. Gloter, J.M. Song, Magnetism and plasmonic performance of mesoscopic hollow ceria spheres decorated with silver nanoparticles, Nanoscale 11 (8) (2019) 3574-3582.

[39] O.M. Ozkendir, E. Cengiz, E. Yalaz, Ö. Söğüt, D.H. Ayas, B.N. Thammajak, Crysta and electronic structure study of $\mathrm{AgAu}$ and $\mathrm{AgCu}$ bimetallic alloy thin films by X-ray techniques, J. Electron Spectrosc. Relat. Phenom. 209 (2016) 53-61.

[40] H. Hu, Z. Wang, L. Pan, S. Zhao, S. Zhu, Ag-Coated Fe3O4@SiO2 Three-Ply Composite Microspheres: Synthesis, Characterization, and Application in Detecting Melamine with Their Surface-Enhanced Raman Scattering, J. Phys. Chem. C 114 (2010) 7738-7742.

[41] J. Chen, Z. Guo, H.B. Wang, M. Gong, X.K. Kong, P. Xia, Q.W. Chen, Multifunctional Fe3O4@C@Ag hybrid nanoparticles as dual modal imaging probes and near-infrared light-responsive drug delivery platform, Biomaterials 34 (2013) 571-581. 